\title{
Effect of wall orientation of the sand concrete lightened by wood shavings on the time lag and the decrement factor
}

\author{
Belkacem Belhadj ${ }^{1,{ }^{*}}$, Adeline Goullieux ${ }^{2}$, Madani Bederina ${ }^{1}$, and Michèle Quéneudec ${ }^{2}$ \\ ${ }^{1}$ SREML Laboratory, University Amar Telidji, Laghouat (Algeria) \\ ${ }^{2}$ Research Unit EPROAD, University of Picardie Jules Verne, Amiens (France)
}

\begin{abstract}
The development of new lightweight concrete based on the valorization of local materials and waste in construction is an environmental and sustainable approach. In this context, the studied composite is a sand concrete (dune and alluvial) lightened by wood shavings to improve its thermophysical properties. The objective is to investigate the orientation effect of an outside wall made with this material in an arid environment on the thermophysical properties of the wall, namely the time lag $(\boldsymbol{\Phi})$ and the decrement factor $(f)$. The experimental study has been dedicated, first of all, to determine the optimal composition of sand concrete lightened by wood shavings, which the content is $60 \mathrm{~kg} / \mathrm{m}^{3}$. This composition is a compromise between studied compactness and workability. Then, to study the thermal properties of the sand concrete without wood shavings (SC-W-WS) and sand concrete lightened by wood shavings (SC-WS). Finally, a numerical simulation using the EnergyPlus software was made to study the wall orientation effect designed in the Laghouat city (south of Algeria). The results obtained show that the substitution of sand by wood shavings has improved thermal properties of the wood sand concrete namely: the thermal conductivity, the specific heat and the thermal diffusivity. The simulation results are very interesting, because all orientations are right for the sand concrete lightened by wood shavings (SC-WS). Nevertheless, the north and the west orientations are wrong in the case of the sand concrete (SC-W-WS). However, the east orientation has the longest time lag, which is consistent with the literature. The advantage of these results is in favour of concrete having improved thermophysical properties.
\end{abstract}

\section{NOMENCLATURE}

\begin{tabular}{|l|l|}
\hline $\boldsymbol{\rho}$ & Density $\left(\mathrm{kg} / \mathrm{m}^{3}\right)$ \\
$\mathbf{k}$ & Thermal conductivity $(\mathrm{W} / \mathrm{mK})$. \\
$\mathbf{c p}$ & Specific heat $(\mathrm{J} / \mathrm{kgK})$. \\
$\mathbf{a}$ & Thermal diffusivity $\left(\mathrm{m}^{2} / \mathrm{s}\right)$ \\
$\mathbf{T}_{\mathbf{e}}$ & Temperature of outside wall surface $\left({ }^{\circ} \mathrm{C}\right)$. \\
$\mathbf{T}_{\mathbf{o}}$ & Temperature of inside wall surface $\left({ }^{\circ} \mathrm{C}\right)$. \\
$\mathbf{T}$ & Temperature $\left({ }^{\circ} \mathrm{C}\right)$ \\
$\mathbf{T}_{\mathbf{i}}$ & Indoor air temperature $\left({ }^{\circ} \mathrm{C}\right)$ \\
$\boldsymbol{T}_{\text {sa }}$ & Sol-air temperature $\left({ }^{\circ} \mathrm{C}\right)$. \\
$\mathbf{x}$ & Wall thickness $(\mathrm{m})$ \\
$\boldsymbol{\Phi}$ & Time lag $(\mathrm{h})$. \\
$\boldsymbol{f}$ & Decrement factor. \\
$\mathbf{t}$ & Time $(\mathrm{h})$. \\
\hline
\end{tabular}

\section{Introduction}

Sustainable building design requires the improvement of thermal comfort and reducing energy consumption. The most important design parameters that affect thermal comfort and energy conservation in the building are: the thermophysical properties of the building envelope material, the site, the building orientation, the distance between buildings and their shape [1].

It should be noted that the building materials of the outside wall of the building are characterize by a complex issue that depends on various criteria, such as thermophysical properties of materials and construction technique of the wall in an arid environment.

In this context, the eco-materials development in construction is an environmental and sustainable approach, whose issues are available in terms of climate change (limiting greenhouse effect), saving natural resources, health and comfort [2]. However, among the objectives of the incorporation of lignocellulosic materials in the cement matrix composites is to get a lightweight concrete, which is an important research topic because of its insulating properties [3].

The studied composite is a sand concrete lightened by addition wood shavings to improve its thermophysical properties. The importance of the first experimental part is limite to the search for the optimal composition of an eco-sand concrete lightened by wood shavings, which is the best compromise between the workability of concrete and density. 
However, two types of concretes was studied, namely: the sand concrete without wood shavings (SCW-WS), which represents the reference concrete and the optimal composition of sand concrete with wood shavings (SC-WS) which wood shavings content is 60 $\mathrm{kg} / \mathrm{m}^{3}$.

The objective of this work is to study the wall orientation effect (case of double wall), realized by the two studied concretes on the thermal inertia properties in an arid region that is the Laghouat city, south of Algeria. This region is characterize by a hot and dry climate in summer, with large daily temperature variations. For this, a numerical simulation study was conducted to determine the two thermal inertia properties, that is thermophysical properties of the wall, namely the time lag $(\boldsymbol{\Phi})$ and the decrement factor $(\boldsymbol{f})$. Note that in hot dry climates, a long time lag or the dephasing $(\boldsymbol{\Phi})$ and a low decrement factor $(f)$ provide thermal comfort for occupants when the outside temperature is hot [4].

\section{Elaboration of the studied concretes}

\subsection{Used materials}

The two types of sand used are local dune sand (DS) that cover a very large part of southern Algeria and the alluvial sand (AS) extracted from M'zi river crossing Laghouat region. The sands are used in admixture in a weight ratio determined by correcting the granulometric curve of alluvial sand, in the thin part, by adding sand dune. The mass ratio AS/DS $=1.7$, where AS is the alluvial sand with a maximum diameter $(5 \mathrm{~mm})$ and DS is the dune sand with a maximum diameter $(0.63 \mathrm{~mm})$.

For sustainable building solutions, Portland limestone cement is usually used (CPC type CPJ CEM/II AL 42.5 $\mathrm{R})$. The $\mathrm{CPC}$ is a new class of cement economic in energy that provides a performance similar to the conventional Portland cement while rejecting $10 \%$ less $\mathrm{CO}_{2}$.

The choice of mineral powders used in this study was inspired by the literature and is based on economic and environmental considerations. The objective is to reduce the use of cement and consequently reduce $\mathrm{CO}_{2}$ emissions. The mineral powders content is $10 \%$ by weight of cement (1/3 limestone, 1/3 natural pozzolan and $1 / 3$ hydraulic lime). Limestone fillers are also used in the concrete composition. The additive used MEDAPLAST-type SP 40, complies with EN 934-2. It is a superplasticizer high range water reducer for obtaining high quality concretes and mortars.

Wood shavings used are an environmentally friendly material and renewable. The wood shavings have woodworking wastes (Fig. 1), found in large quantities and can constitute an environmental discomfort when they are burned. The water absorption coefficient of the wood shavings is $330 \%$.

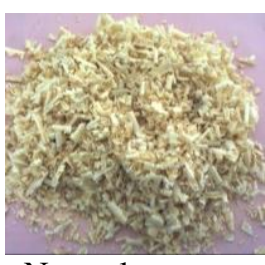

Normal aspect

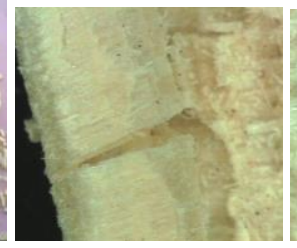

$\mathrm{G}=50$

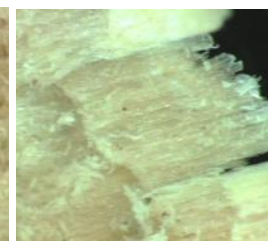

$\mathrm{G}=100$
Fig. 1. General aspect of wood shavings.

\subsection{Compositions of the studied concretes}

In this study, the addition of wood shavings was performed by substitution with sand. The value of the ratio sand/wood shavings was determined by the absolute volumes formula. The content for wood shavings was limited to a content of $60 \mathrm{~kg} / \mathrm{m}^{3}$, given its favorable effect on workability with a slump $6 \mathrm{~cm}$ at Abrams cone. In summary the different values of the materials used for elaboration of the studied concretes are summarize in Table 1.

Table 1. Compositions of the studied concretes.

\begin{tabular}{|l|c|c|}
\hline Studied concretes types & SC-W-WS & SC-WS \\
\hline Sand $\left(\mathrm{kg} / \mathrm{m}^{3}\right)$ & 1316 & 1030 \\
\hline Cement $\left(\mathrm{kg} / \mathrm{m}^{3}\right)$ & 315 & 315 \\
\hline Minerals powders $\left(\mathrm{kg} / \mathrm{m}^{3}\right)$ & 35 & 35 \\
\hline Limestone filler $\left(\mathrm{kg} / \mathrm{m}^{3}\right)$ & 135 & 135 \\
\hline Total water $\left(1 / \mathrm{m}^{3}\right)$ & 210 & 288 \\
\hline wood shavings $\left(\mathrm{kg} / \mathrm{m}^{3}\right)$ & 0 & 60 \\
\hline SP $*(\%)$ & 2 & 2 \\
\hline
\end{tabular}

* Percentage based on weight of cement and mineral powders.

The mixing procedure was inspired by previous work [5]. After mixing, the material was poured into molds. The specimens was demoulded after $24 \mathrm{~h}$.

\section{Numerical simulation}

\subsection{Time lag and decrement factor}

In this study, the heat flux through the wall was assumed in one direction $(\mathrm{x})$ and depends on the time $(\mathrm{t})$. For this problem, the equation of heat transfer by conduction is, therefore, a function of $(\mathrm{T}, \mathrm{t}, \mathrm{x})$, it is written as follows [4]:

$$
k \frac{\partial^{2} T}{\partial x^{2}}=\rho c_{P} \frac{\partial T}{\partial t},
$$

When (k) is the thermal conductivity, $(\rho)$ is the density and (cp) is the specific heat of the material constituting the wall. To solve this problem, two boundary conditions and an initial condition are require [4]: 


$$
\begin{aligned}
& k\left(\frac{\partial T}{\partial x}\right)_{x=0}=h_{\mathrm{i}}\left[T_{x=0}(t)-T \mathrm{i}\right] . \\
& k\left(\frac{\partial T}{\partial x}\right)_{x=L}=h_{\mathrm{o}}\left[T_{\mathrm{sa}}(t)-T\right.
\end{aligned}
$$

When $h_{i}$ is the coefficient of heat transfer by convection to the inside wall surface, $\mathrm{h}_{\mathrm{o}}$ is the coefficient of heat transfer by convection from the outside wall surface, $\mathrm{Tx}=0$ is the temperature of the inside wall surface, $\mathrm{Tx}=\mathrm{L}$ is the temperature of the outside wall surface, $\mathrm{Ti}$ is the temperature of the "test room", and Tsa (t) is the sol-air temperature.

The time lag $(\boldsymbol{\Phi})$ and the decrement factor $(\boldsymbol{f})$ are two very important factors of the wall, which determine the thermal storage capacity for materials. They are shown schematically in Fig. 2.

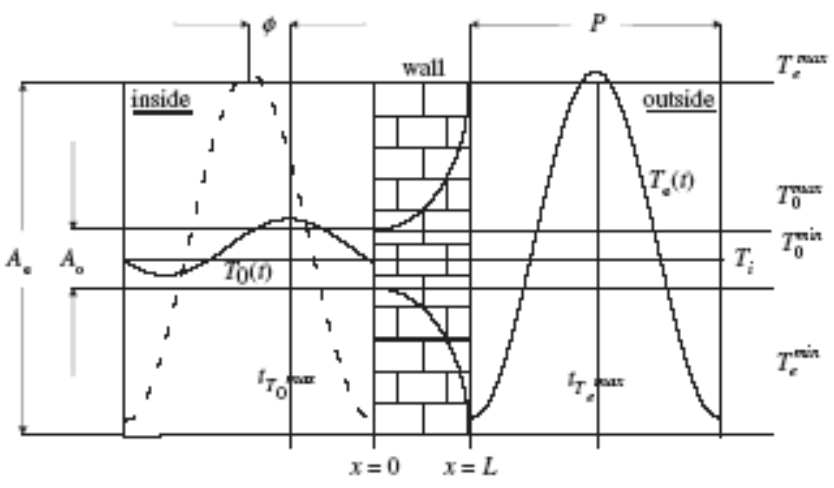

Fig. 2. Schematic representation time lag $(\boldsymbol{\Phi})$ and decrement factor $(f)$ [4].

The time it takes the heat flux to propagate from the outside surface to the inside surface, is named "time lag" or "dephasing". It is calculated by the following equation $[4,6]$ :

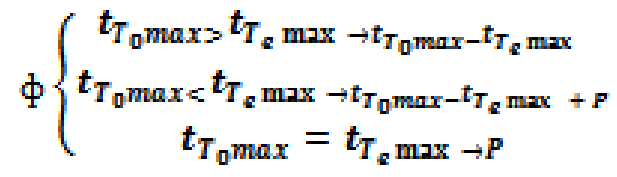

With $(\boldsymbol{\Phi})$ : time lag in hours;

$t_{\text {Temax }}$ : Time when the temperature of outside surface of the wall is maximum;

$t_{\text {Tomax }}$ : Time when the temperature of inside wall surface is maximum.

During the propagation of the heat flux from the outside wall surface to the inside wall surface for a period P (24 hours), its amplitude will decrease according to the thermophysical properties of building materials. This means that when the flow reaches the inside surface of the wall, it will have considerably low amplitude than the amplitude of the outside surface of the wall $[4,6]$. The decrement factor $(f)$ was determined by the following equation:

$$
f=\frac{A_{o}}{A_{\mathrm{e}}}=\frac{T_{\mathrm{o}}^{\mathrm{max}}-T_{\mathrm{o}}^{\mathrm{min}}}{T_{\mathrm{e}}^{\mathrm{max}}-T_{\mathrm{e}}^{\min }},
$$

When are the amplitudes of the heat flux to the surfaces, inside and outside of the wall. It should be noted that the heat flux on the outside wall surface, includes the temperature of the outside air combined periodically with solar radiation and convection between the air of the outside wall surface and the outside air.

\subsection{Simulation software}

In this study, the numerical simulation was made for a summer day, whose the maximum and minimum outdoor temperature are respectively $42.5^{\circ} \mathrm{C}$ and $25.2^{\circ} \mathrm{C}$, for a supposed wall located in the Laghouat city, in southern Algeria. The geographical coordinates of Laghouat city are Latitude $33.80^{\circ} \mathrm{N}$, Longitude $2.87^{\circ} \mathrm{E}$ and Altitude $765 \mathrm{~m}$. This study is made for two types of wall designed with the studied concretes.

The thickness envisaged for the double wall without coatings is $25 \mathrm{~cm}$ (10 cm concrete $+5 \mathrm{~cm}$ air-gap +10 $\mathrm{cm}$ concrete) and the double wall with coatings $(27 \mathrm{~cm})$ [7]. By using the EnergyPlus software (Version 1.2.2.030), we can get through time, in hours of the day, the temperature of the outside wall surface, the temperature of the inside wall surface and the temperature of the indoor air of cell "test room", whose dimensions are $(2 \times 2 \times 2.5 \mathrm{~m})$. The envelope of the cell has a door $(0.60 \times 1.70 \mathrm{~m})$ in the wall oriented to the south.

\section{Results and discussion}

\subsection{Physical and mechanical properties}

The results of the physico-mechanical properties of the studied concretes are shown in Table 2. Since the studied concretes are intended for the construction of the housing built in arid environments, the main thermal interpretation of results will focus on the values of the thermal diffusivity. This thermal property characterizes the concept of thermal inertia properties, the value of which is interesting for the concrete (SC-WS) with a $46 \%$ reduction compared to reference concrete (SC-WWS). Furthermore, and as expected, when the density decreases, the compressive strength also decreases.

Table 2. Physical and mechanical properties of the studied concretes.

\begin{tabular}{|l|c|c|}
\hline \multicolumn{1}{|c|}{ Studied concretes types } & SC-W-WS & SC-WS \\
\hline Thermal conductivity $(\mathrm{W} / \mathrm{mK})$ & 1.40 & 0.80 \\
\hline Specific heat $(\mathrm{J} / \mathrm{kgK})$ & 1209 & 1876 \\
\hline Thermal diffusivity $10^{-6}\left(\mathrm{~m}^{2} / \mathrm{s}\right)$ & 0.578 & 0.311 \\
\hline Dry density $\left(\mathrm{kg} / \mathrm{m}^{3}\right)$ & 2003 & 1368 \\
\hline Compressive strength $(\mathrm{MPa})$ & 21.58 & 6.45 \\
\hline
\end{tabular}




\subsection{Effect of wall orientation}

In arid environments, the advantage is in favour of the double wall due to the reduced values of the decrement factor in different orientations $[7,8]$. The study of the effect of wall orientation was made for double wall without coatings. The simulation results shown in Fig. 3 to Fig. 6, and equations (3 and 4) was used to calculate the time lag $(\boldsymbol{\Phi})$ and the decrement factor $(\boldsymbol{f})$ of the various walls (SC-WS). Summary, the results of the numerical simulation are reported in Table 3 with the various improvements.

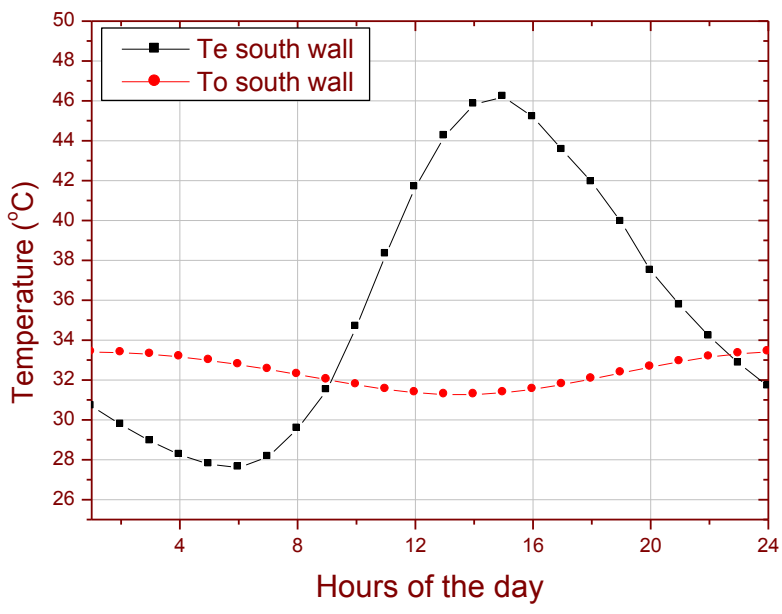

Fig. 3. Temperature of outside and inside wall surface by (SC-WS) of south orientation.

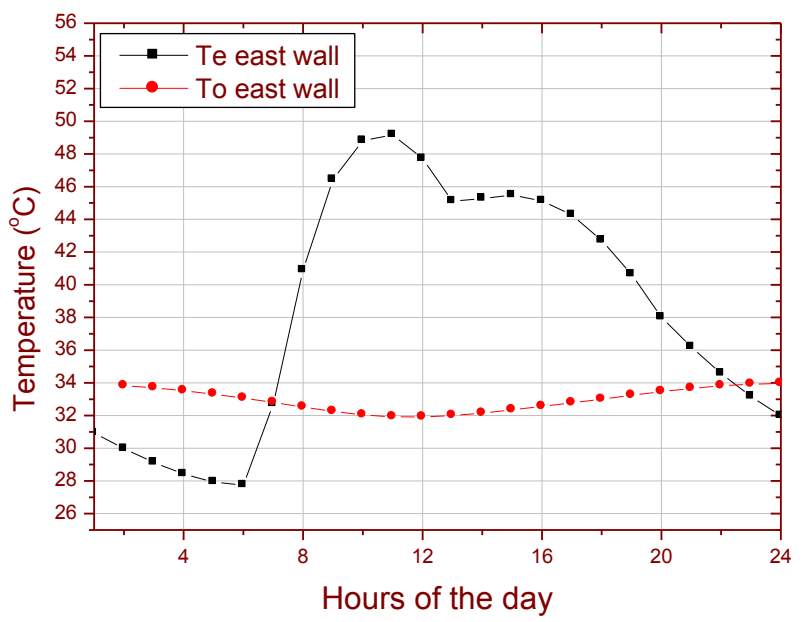

Fig. 4. Temperature of outside and inside wall surface by (SC-WS) of east orientation.

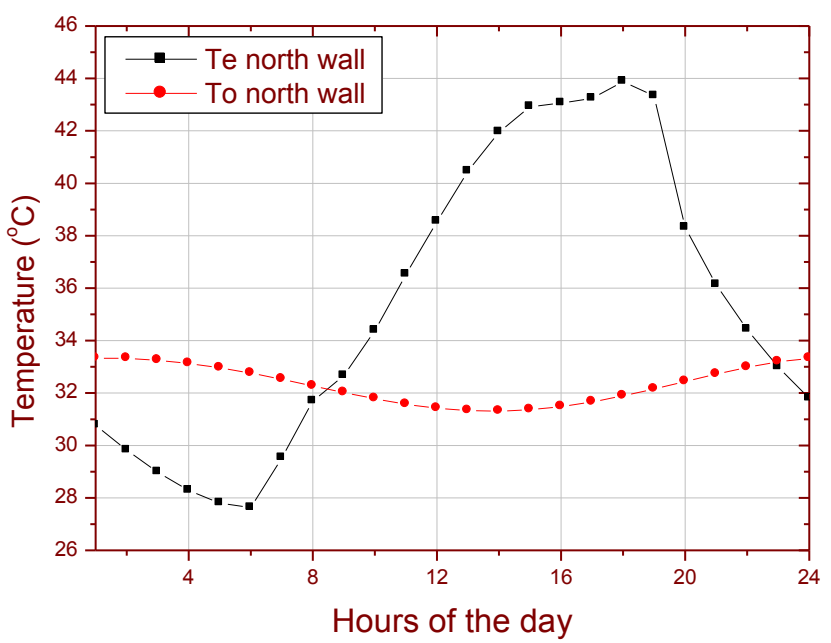

Fig. 5. Temperature of outside and inside wall surface by (SC-WS) of north orientation.

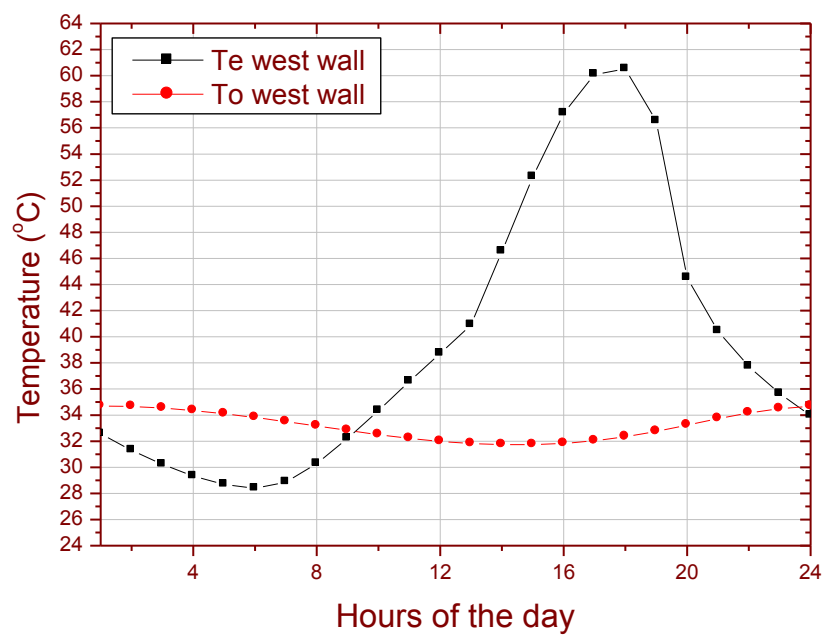

Fig. 6. Temperature of outside and inside wall surface by (SC-WS) of west orientation.

Table 3. Time lag and decrement factor for different orientations of the double wall without coatings.

\begin{tabular}{|c|c|c|c|c|}
\hline \multicolumn{2}{|l|}{ Wall } & SC-W-WS & SC-WS & Improvement \\
\hline South & $\boldsymbol{\Phi}$ & $8 \mathrm{~h}$ & $9 \mathrm{~h}$ & $+1 \mathrm{~h}$ \\
\cline { 2 - 5 } Wall & $\boldsymbol{f}$ & 0.177 & 0.115 & $-35 \%$ \\
\hline East & $\boldsymbol{\Phi}$ & $12 \mathrm{~h}$ & $13 \mathrm{~h}$ & $+1 \mathrm{~h}$ \\
\cline { 2 - 5 } Wall & $\boldsymbol{f}$ & 0.146 & 0.095 & $-34 \%$ \\
\hline North & $\boldsymbol{\Phi}$ & $6 \mathrm{~h}$ & $7 \mathrm{~h}$ & $+1 \mathrm{~h}$ \\
\cline { 2 - 5 } Wall & $\boldsymbol{f}$ & 0.188 & 0.123 & $-34 \%$ \\
\hline West & $\boldsymbol{\Phi}$ & $5 \mathrm{~h}$ & $7 \mathrm{~h}$ & $+2 \mathrm{~h}$ \\
\cline { 2 - 5 } Wall & $\boldsymbol{f}$ & 0.146 & 0.091 & $-37 \%$ \\
\hline
\end{tabular}


The best compromise between the time lag and the decrement factor for the double wall without coatings, for the two studied concrete are the south orientation and the east orientation, when considering the time lag that is $\geq 8$ hours according to the climatic zone [9]. However, the wrong orientations are the north and the west. The advantage of the results is in favour of concrete with improved thermophysical properties.

Note that the long time lag is at benefit of the orientation east, which is consistent with the literature $[7,10]$.

\subsection{Effect of coatings addition}

The addition of the outside and inside coating thickness of $1 \mathrm{~cm}$ each increases the thickness of the double wall from 25 to $27 \mathrm{~cm}$. Thermophysical properties of cement mortar as the outside coating are $\mathrm{k}=1.4 \mathrm{~W} / \mathrm{mK}, \mathrm{cp}=$ $1200 \mathrm{~J} / \mathrm{kg} . \mathrm{K}$ and $\rho=2100 \mathrm{~kg} / \mathrm{m}^{3}$, and the plaster as the inside coating are $\mathrm{k}=0.05 \mathrm{~W} / \mathrm{mK}, \mathrm{cp}=1000 \mathrm{~J} / \mathrm{kg} . \mathrm{K}$ and $\rho=1300 \mathrm{~kg} / \mathrm{m}^{3}$.

According to the simulation results summarized in Table 4 with various improvements, the right orientations that represent the best compromise between the time lag and the decrement factor for double wall with outside and inside coatings are the south, the east, the north and the west for (SC-WS).

Table 4. Time lag and decrement factor for different orientations of double wall with coatings.

\begin{tabular}{|c|c|c|l|c|}
\hline \multicolumn{2}{|l|}{ Wall } & SC-W-WS & SC-WS & Improvement \\
\hline South & $\boldsymbol{\Phi}$ & $9 \mathrm{~h}$ & $11 \mathrm{~h}$ & $+2 \mathrm{~h}$ \\
\cline { 2 - 5 } Wall & $\boldsymbol{f}$ & 0.157 & 0.101 & $-35 \%$ \\
\hline East & $\boldsymbol{\Phi}$ & $12 \mathrm{~h}$ & $13 \mathrm{~h}$ & $+1 \mathrm{~h}$ \\
\cline { 2 - 5 } Wall & $\boldsymbol{f}$ & 0.134 & 0.086 & $-35 \%$ \\
\hline North & $\boldsymbol{\Phi}$ & $6 \mathrm{~h}$ & $8 \mathrm{~h}$ & $+2 \mathrm{~h}$ \\
\cline { 2 - 5 } Wall & $\boldsymbol{f}$ & 0.168 & 0.110 & $-34 \%$ \\
\hline West & $\boldsymbol{\Phi}$ & $6 \mathrm{~h}$ & $8 \mathrm{~h}$ & $+2 \mathrm{~h}$ \\
\cline { 2 - 5 } Wall & $\boldsymbol{f}$ & 0.128 & 0.081 & $-36 \%$ \\
\hline
\end{tabular}

This explains the beneficial effect of the inside and outside coatings for concrete having improved thermophysical properties. These results are best than the results of an outside wall of barley straw sand concrete [7], because the time lag $(\boldsymbol{\phi}) \geq 8$ h for all orientations.

\subsection{Synthesis}

\subsubsection{Climate zoning}

For best thermal comfort with reduced energy consumption, so you have the spaces according to their energy needs, that is to say, the need to develop a "climate zoning" by combining the habitable spaces following the south orientation and the east, as well as the service spaces (buffer zones) for the north orientation and west (Fig. 7).

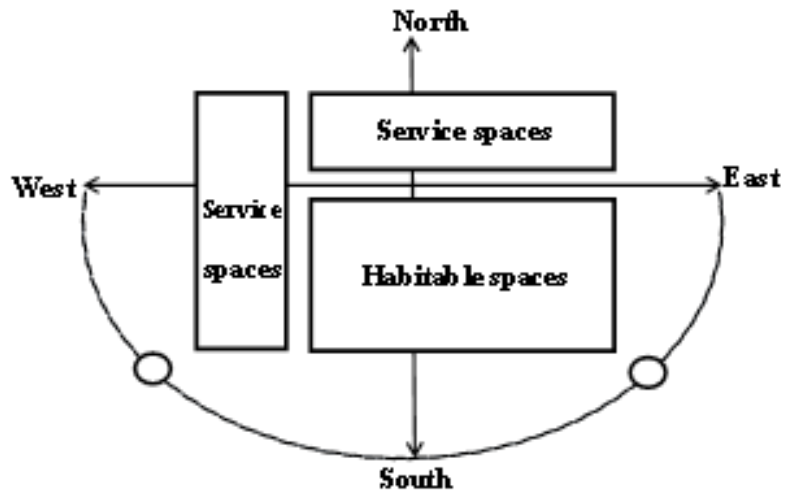

Fig. 7. Climate zoning [9].

Moreover, this finding on the preferred orientation is consistent with the recommendation of the literature [7,9]. This recommendation from the literature is consistent with sand concrete without wood shavings. Nevertheless, for the sand concrete lightened by the wood shavings all the orientations are right.

\subsubsection{Advantage and development of the wood sand concrete}

The development of a new eco-sand concrete based on wood shavings, which is considere as an insulatingbearer lightweight sand concrete, may led to many benefits, such as the use of local materials that are available in large quantities and at low cost, reuse of industrial waste, reduction of $\mathrm{CO}_{2}$ emissions, durability of building materials and finally reducing the energy consumption during the production phase and operating through the development of a building material for the outside wall of a building possessing a long time lag and a low decrement factor.

Indeed, in arid environments, this type of lightweight concrete allows to minimize the impact of outside climate factors and thus contributes to improve the thermal comfort level and decreases energy consumption. Note that the materials developed are interesting by their thermal behavior. Their mechanical characteristics also allow a compatible design with modern constructions.

\section{Conclusions}

The results presented herein show that the addition of wood shavings by substitution with sand (with the studied proportion), considerably improves the thermophysical properties of the sand concrete. The thermal conductivity and the thermal diffusivity were reduced $42 \%$ and $46 \%$ while the specific heat was increased $55 \%$.

Based on numerical simulation, one can conclude that the determination of the two thermal properties, ie, the time lag and the decrement factor are very important to know, because they determine the thermal inertia properties of the outside wall. 
The results of numerical simulation are consistent with the literature for different orientations of the double wall without coatings. The advantage of these results is in favour of the concrete with improved thermophysical properties. However, for the double wall with coatings for the sand concrete lightened by wood shavings, all orientations are right, from where the material can face the vagaries of adverse weather conditions.

However, the requirements of a sustainable construction is to minimize the outside climatic effects and therefore to minimize energy consumption, it is therefore necessary to provide eco-materials having reduced thermal conductivity and high specific heat in order to have a high thermal inertia.

Finally, it should be noted that the obtained results are encouraging, promising in the eco-design option and are widely incentives to promote this type of wood sand concrete, as it is possible to design passive houses using the two basic principles of bioclimatic architecture in arid environment: thermal inertia and wall orientation. This approach that we can qualify as eco-architectural, contributes favourably to improve the thermal comfort level and the reduction of energy consumption in houses, in the south of Algeria.

\section{KEYWORDS}

Wood sand concrete, Wood shavings, Wall orientation, Arid environment, Thermophysical properties, Time lag, Decrement factor, EnergyPlus software.

\section{References}

1. G. Manioglu, Z. Yilmaz. Energy efficient design strategies in the hot dry area of Turkey. Building and Environment. 43 (2008) 1301-1309.

2. G. Escadeillas, Eco materials in construction: challenges and prospects, in: Seventh Edition of the Scientific Meetings of the Group Franccophone for Research and Training on Concrete $(\mathrm{RF})^{2} \mathrm{~B}, 19-20$ June Toulouse, France, 2006 (In French).

3. M. Khazma, A. Goullieux, R.M. Dheilly, B. Laidoudi, M. Queneudec. Impact of aggregate coating with a PEC elastomer on properties of lightweight flax shive concrete. Industrial crops and Products. 33 (2011) 49-56.

4. H. Asan, Investigation of wall's optimum insulation position from maximum time lag and decrement factor. Building and Environment. 32 (2000) 197203.

5. B. Belhadj, M. Bederina, N. Montrelay, J. Houessou, M. Quéneudec. Effect of substitution of wood shavings by barley straws on the physicomechanical properties of lightweight sand concrete. Construction and Building Materials. 66 (2014) 247258.
6. H. Asan, Numerical computation of time lag and decrement factors for deferent building materials. Building and Environment. 41 (2006) 915-920.

7. B. Belhadj, M. Bederina. Z. Makhloufi. A. Goullieux, M. Quéneudec. Study of the thermal performance of an exterior wall of barley straw sand concrete in an arid environment. Energy and Buildings. 87 (2015) 166-175.

8. Hamida Ben Cheikh, Belhadj Belkacem, Khenfer Med Mouldi. The effect of alleviating the sand concrete by wood shavings on wall time lag and decrement factor. Civil and Environmental Research. Vol.5 (2013) 16-20.

9. S. Mazouz. Elements of Architectural Design. Office of University Publications, Algeria, 2004. (In French)

10. L.E. Mavromatidis, M. El Mankibi, P. Michel, M. Santamouris, of time lags and decrement factors for wall complexes including multilayer thermal insulation, in two different climatic zones. Applied Energy. 92 (2012) 480-491. 